\title{
FRACTOGRAPHY ANALYSIS OF AW-7020 ALLOY JOINTS WELDED BY FSW
}

\author{
Krzysztof Dudzik, Adam Charchalis
}

\author{
Gdynia Maritime University, Faculty of Marine Engineering \\ Morska Street 81-87, 81-225 Gdynia, Poland \\ tel.: +48586901549, +485869013 47, fax: +48586901399 \\ e-mail:kdudzik@am.gdynia.pl,achar@am.gdynia.pl
}

\begin{abstract}
Technology development of Friction Stir Welding (FSW) method for joining AW-7020 aluminum alloy elements was described. Two kinds of tools were used during research: with a regular pin and with a „TRI-FLUTE” pin. Tools were with different dimensions and the following parameters changed mandrel's rotary speed $V_{n}[\mathrm{rev} / \mathrm{min}]$, welding speed $V_{z}[\mathrm{~mm} / \mathrm{min}]$, angle of tool deflection $\alpha_{z}\left[^{\circ}\right]$. The thickness of the joining sheets was $g=12 \mathrm{~mm}$. The sheets were one side milled to a thickness of $10 \mathrm{~mm}$ in the contact portion.

Samples were tested by Charpy impact strength according to PN-EN ISO 148-1:2010. After these tests, the samples were analysed by means of fractographic examination. The tests were made with using a scanning electron microscope (SEM) Philips XL-30. The analysis has shown that there is the influence of the joining parameters and chosen tools for the possibility of occurrence welding defects in joints. Welding defects detected in the structure of joints after impact studies were: incomplete fusion, separations dissection, and cracks.

During the development of friction stir welding technology, the best results, in terms of structure homogeneity and the absence of welding defects, were achieved for the tool with TRI-FLUTE pin and joining parameters:

$V_{n}=450 \mathrm{rev} / \mathrm{min}, V_{z}=180 \mathrm{~mm} / \mathrm{min}, \alpha_{z}=88.5^{\circ}$.
\end{abstract}

Keywords: Friction Stir Welding (FSW), aluminum alloys, welding, fractography, scanning electron microscopy

\section{Introduction}

Aluminum alloys are getting more and more interest in the shipbuilding industry as these alloys allow a significant reduction in ship structure weight compared with the weight of steel structures. The use of aluminum reduces the weight by about $50 \%$, thereby increasing the displacement of the vessel and maintaining the displacement for load or speed increase and stability improvement.

Joining aluminum and its alloys with welding methods is difficult due to its specific properties. The main problems that can occur during welding result from the following factors: high similarity of aluminum to oxygen, the creation of high-melting $\left(2060^{\circ} \mathrm{C}\right)$ oxide $\mathrm{Al}_{2} \mathrm{O}_{3}$, high thermal conductivity, high thermal expansion of aluminum alloys, big casting shrinkage (being the reason of welding strains and stresses), considerable decrease of resistance at welding temperatures, the loss of alloying elements such as magnesium, zinc, or lithium during welding. The aforementioned main drawbacks related to aluminum alloys welding provoke searching other joining methods for these materials. An alternative to butt-welding is a method known as friction stir welding (FSW). The method was developed and patented in 1991 in the Welding Institute (TWI) at Cambridge University. For this method of heating and plasticizing a material, a special tool with rotating pin placed in the joining point of pressed down sheets was used. After setting the tool in rotating motion, heating with friction heat and plasticizing sheets material in the direct contiguity - a slow displacement of the whole system alongside the contact line takes place [1-3]. FSW is a method of welding in a solid state of mainly aluminum alloys, copper alloys, and stainless steel. The main advantage of this method is the fact that it is easy to obtain welds of high, repeatable properties [47]. However, it is important to the proper selection of appropriate tools and welding parameters.

The aim of this paper is to develop a Friction Stir Welding technology for joining AW-7020 
aluminum alloy elements. It consists in choosing the tools and joining parameters for achieving joints free from welding defects.

\section{The research methodology}

The testing used EN AW-7020 T6 aluminum alloy (supersaturated and artificially aged) the chemical composition of the alloy is given in Tab. 1.

Tab. 1. Chemical composition of 7020 aluminum alloy

\begin{tabular}{|c|c|c|c|c|c|c|c|c|c|}
\hline \multicolumn{10}{|c|}{ Chemical composition (\%) } \\
\hline $\mathrm{Si}$ & $\mathrm{Fe}$ & $\mathrm{Cu}$ & $\mathrm{Mn}$ & $\mathrm{Mg}$ & $\mathrm{Cr}$ & $\mathrm{Zn}$ & $\mathrm{Ti}$ & $\mathrm{Zr}$ & $\mathrm{Al}$ \\
\hline 0.30 & 0.35 & 0.10 & 0.24 & 1.30 & 0.14 & 4.70 & 0.08 & 0.07 & the rest \\
\hline
\end{tabular}

Technology development of Friction Stir Welding (FSW) method for joining AW-7020 aluminum alloy elements was carried out using a conventional vertical milling machine FYF32JU2, adapted for FSW. A view of the rotating mandrel head and table with fixed joined sheets is shown in Fig. 1. The FSW machine is equipped with the necessary instrumentation: handles rigid mounting plates and tool cooling system.

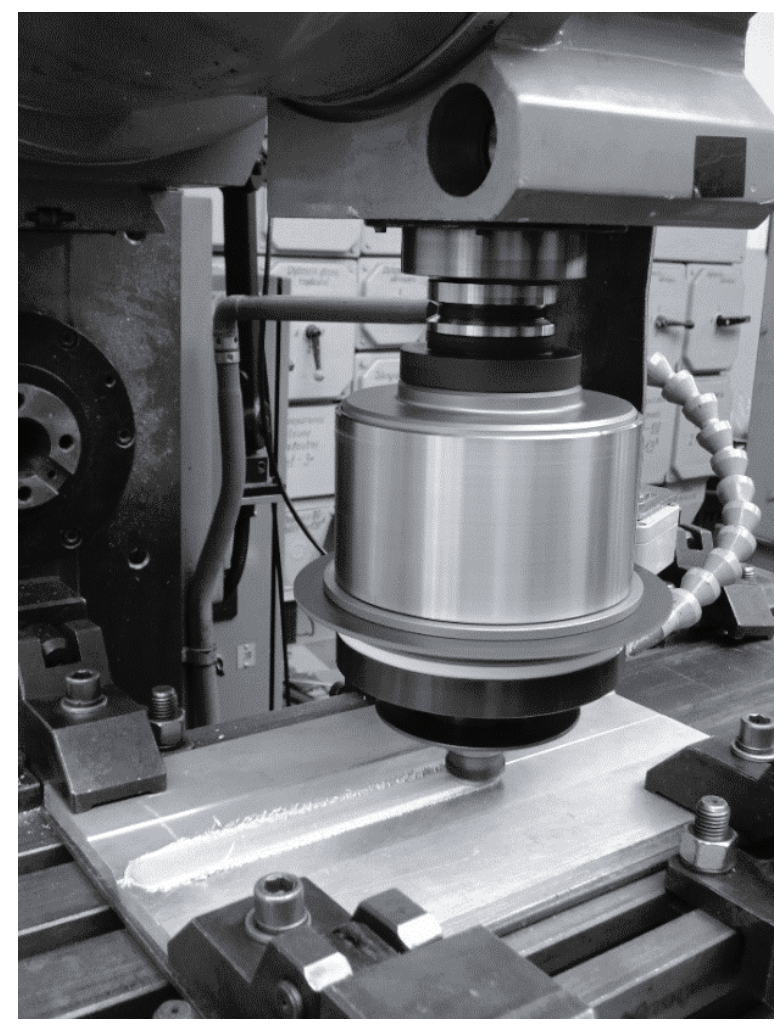

Fig. 1. FSW machine used in research

During research tools made of high speed steel HS6-5-2 (SW7M) were used. As shown by preliminary tests, the tool made of such steel is equivalent to the welding tools designed for the friction stir welding of aluminum alloys $5 \mathrm{xxx}$ and $7 \mathrm{xxx}$ series. This means that it is capable of withstanding temperatures in which the plastic deformation process occurs, mixing and forcing the metal around the mandrel, and there is no excess bonding material to the tool shoulder. Two kinds of tools were used: with a regular pin and with a „TRI-FLUTE” pin, which shapes are shown in Fig. 2. 


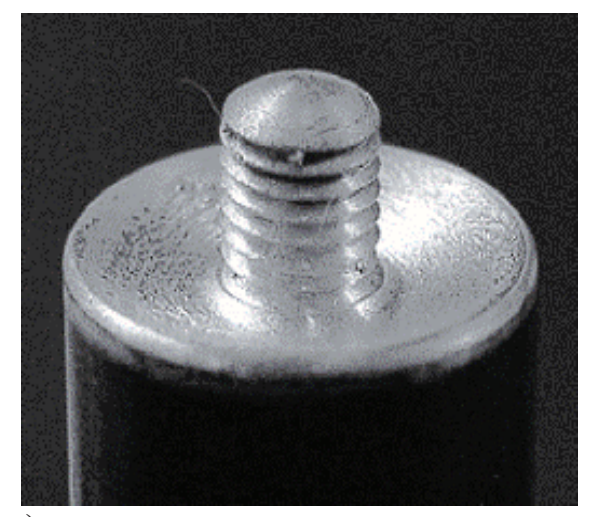

a)

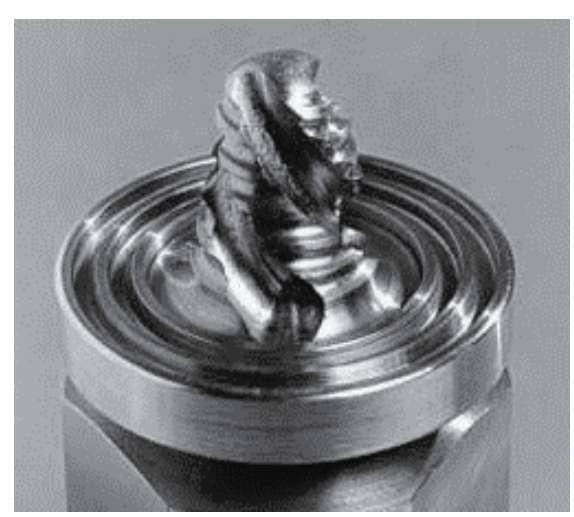

b)

Fig. 2. Tools shapes used in research: a) with a regular pin, b) with TRI-FLUTE” pin

Dimensions of the characteristic parameters of the tools used for butt welding 7020 aluminum alloy plates are shown in Tab. 2. During research, the following parameters changed:

- mandrel's rotary speed $\mathrm{V}_{\mathrm{n}}$ [rev/min]: 440, 450, 560, 710, 900,

- welding speed $\mathrm{V}_{\mathrm{z}}[\mathrm{mm} / \mathrm{min}]: 140 ; 180 ; 224$,

- angle of tool deflection $\alpha_{z}\left[{ }^{\circ}\right]: 88$ and 88.5.

Tab. 2. Tools dimensions used in research

\begin{tabular}{|c|c|c|c|}
\hline \multirow{2}{*}{ Tool type } & $\begin{array}{c}\text { Shoulder diameter } \\
\mathrm{D}[\mathrm{mm}]\end{array}$ & $\begin{array}{c}\text { Pin diameter } \\
\mathrm{d}[\mathrm{mm}]\end{array}$ & $\begin{array}{c}\text { Pin length } \\
\mathrm{h}[\mathrm{mm}]\end{array}$ \\
\hline \multirow{4}{*}{ Regular pin } & 20.0 & 6.0 & 3.0 \\
\cline { 2 - 4 } & 20.0 & 6.0 & 6.0 \\
\cline { 2 - 4 } & 20.0 & 6.0 & 8.6 \\
\cline { 2 - 4 } & 26.0 & 9.0 & 8.6 \\
\hline TRI-FLUTE & 25.0 & 10.0 & 5.8 \\
\hline
\end{tabular}

All joints were both sides welded, using the same and different parameters and tools on both sides of the joined elements.

Preliminary research allowed to selected tool and the parameters for which the best results were obtained (Tab. 3). The best tool for friction stir welding 7020 alloy sheets proved to be a new type of tool with TRI-FLUTE pin. FSW joining for further testing was repeated using this kind of tool and with the parameters obtained in a preliminary study.

The thickness of the joining sheets was $\mathrm{g}=12 \mathrm{~mm}$. The sheets were one side milled to a thickness of $10 \mathrm{~mm}$ in the contact portion. Accordingly, rigid mounting plate was ensured by welding machine equipment. Except to providing general cleanliness of the sheets there was not used any degreasing agent interfaces connected elements. Plates were joined on both sides with the same parameters, which are shown in Tab. 3. The diagram of friction stir welding is shown in Fig. 3. View of the sheets joined by FSW is shown in Fig. 4.

Tab. 3. Chosen FSW parameters of 7020 aluminum alloy sheets

\begin{tabular}{|c|c|c|c|c|c|}
\hline \multicolumn{3}{|c|}{ Tool dimensions } & \multirow{2}{*}{$\begin{array}{c}\text { Angle of tool } \\
\text { deflection } \\
\alpha_{z} \\
\left.{ }^{\circ}\right]\end{array}$} & \multirow{2}{*}{$\begin{array}{c}\text { Mandrel's } \\
\text { rotary speed } \\
\mathrm{V}_{\mathrm{n}} \\
{[\mathrm{rpm}]}\end{array}$} & \multirow{2}{*}{$\begin{array}{c}\text { Welding speed } \\
\mathrm{V}_{\mathrm{z}} \\
{[\mathrm{mm} / \mathrm{min}]}\end{array}$} \\
\hline $\begin{array}{c}\mathrm{D} \\
{[\mathrm{mm}]}\end{array}$ & $\begin{array}{c}\mathrm{d} \\
{[\mathrm{mm}]}\end{array}$ & $\begin{array}{c}\mathrm{h} \\
{[\mathrm{mm}]}\end{array}$ & & & \\
\hline 25 & 10 & 5.8 & 88.5 & 450 & 180 \\
\hline
\end{tabular}




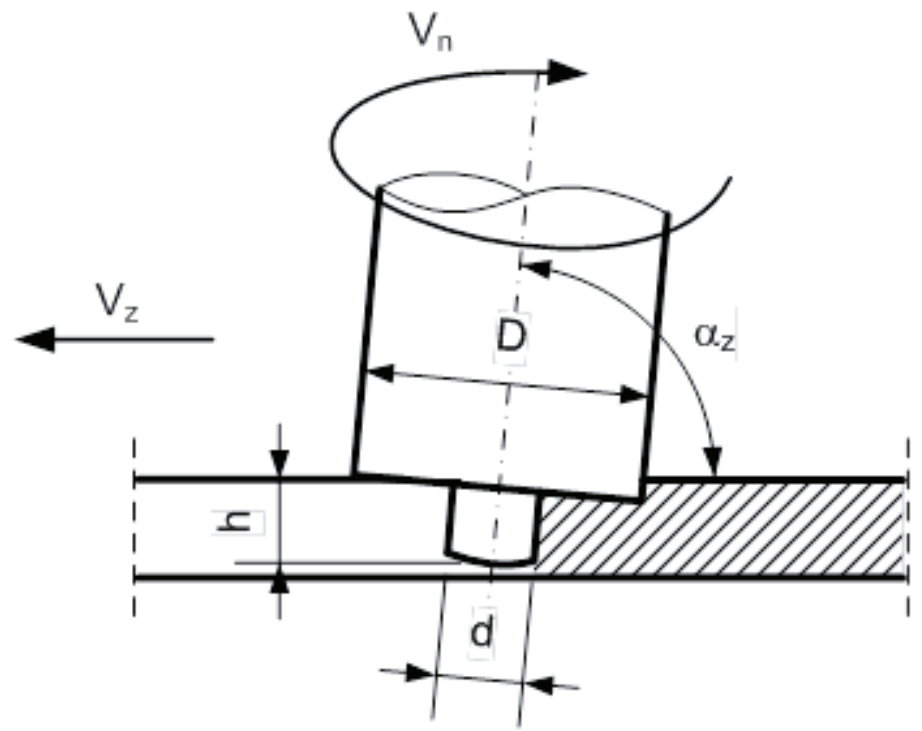

Fig. 3. The diagram of FSW [77]

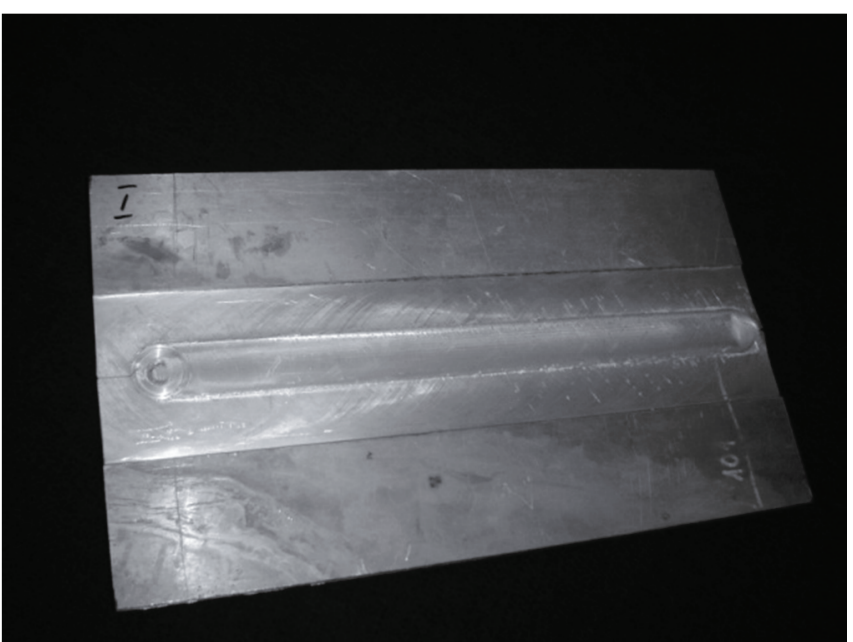

Fig. 4. View of the sheets joined by FSW

Samples of AW-7020 alloy joined by friction stir welding method using different tools and parameters were tested by Charpy impact strength according to PN-EN ISO 148-1:2010. Impact test samples were performed as standard, with dimensions of $55 \times 10 \times 10 \mathrm{~mm}$, in which a notch was cut in the $\mathrm{V}$ - shape. The experiment was conducted at a temperature of $+20^{\circ} \mathrm{C} \pm 2$.

After these tests, the samples were analysed by means of fractographic examination. The tests were made with using a scanning electron microscope (SEM) Philips XL-30 equipped with a tungsten electron gun. The tests were performed in a high vacuum using SE detector (secondary electrons), dedicated to the topography of the surface.

\section{The research results}

The characteristic fractures of chosen samples obtained from the scanning electron microscope are shown in Fig. 5-10.

Fracture of sample with proper structure - without welding defects is shown in Fig. 5. This sample was joined using TRI - FLUTE tool on both sides with the same parameters:

- tool parameters: $\mathrm{D}=20 \mathrm{~mm}, \mathrm{~d}=6 \mathrm{~mm}, \mathrm{~h}=5.8 \mathrm{~mm}$,

- joining parameters: $\mathrm{V}_{\mathrm{n}}=450 \mathrm{rev} / \mathrm{min}, \mathrm{V}_{\mathrm{z}}=180 \mathrm{~mm} / \mathrm{min}, \alpha_{\mathrm{z}}=88.5^{\circ}$. 


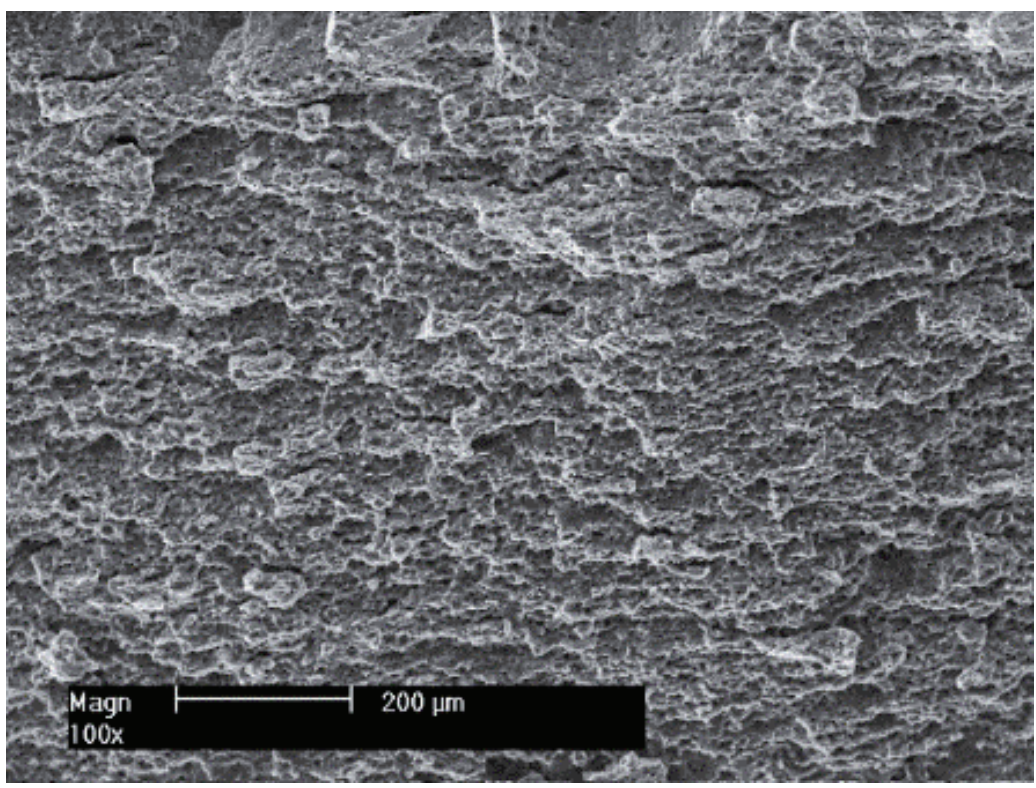

Fig. 5. Fracture of sample without welding defects

Fracture of sample with welding defect - incomplete fusion, is shown in Fig. 6. This sample was joined using two tools with regular pins.

One side:

- tool parameters: $\mathrm{D}=20 \mathrm{~mm}, \mathrm{~d}=6 \mathrm{~mm}, \mathrm{~h}=3 \mathrm{~mm}$,

- joining parameters: $\mathrm{V}_{\mathrm{n}}=560 \mathrm{rev} / \mathrm{min}, \mathrm{V}_{\mathrm{z}}=180 \mathrm{~mm} / \mathrm{min}, \alpha_{\mathrm{z}}=88^{\circ}$.

Second side:

- tool parameters: $\mathrm{D}=20 \mathrm{~mm}, \mathrm{~d}=6 \mathrm{~mm}, \mathrm{~h}=6 \mathrm{~mm}$,

- joining parameters: $\mathrm{V}_{\mathrm{n}}=560 \mathrm{rev} / \mathrm{min}, \mathrm{V}_{\mathrm{z}}=140 \mathrm{~mm} / \mathrm{min}, \alpha_{\mathrm{z}}=88^{\circ}$.

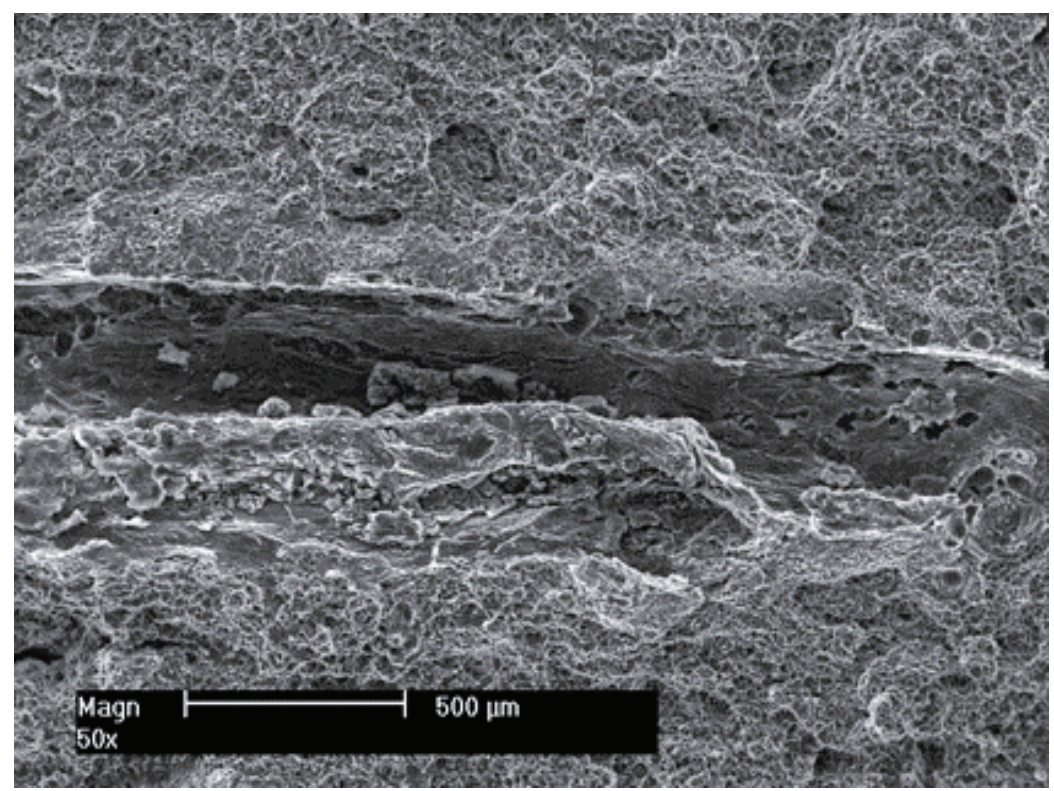

Fig. 6. Fracture of sample with welding defect-incomplete fusion

Fracture of sample with welding defect - incomplete fusion, is shown in Fig. 7. This sample was joined using two tools with regular pins.

One side:

- tool parameters: $\mathrm{D}=20 \mathrm{~mm}, \mathrm{~d}=6 \mathrm{~mm}, \mathrm{~h}=3 \mathrm{~mm}$,

- joining parameters: $\mathrm{V}_{\mathrm{n}}=710 \mathrm{rev} / \mathrm{min}, \mathrm{V}_{\mathrm{z}}=140 \mathrm{~mm} / \mathrm{min}, \alpha_{\mathrm{z}}=88^{\circ}$. 
Second side:

- tool parameters: $\mathrm{D}=20 \mathrm{~mm}, \mathrm{~d}=6 \mathrm{~mm}, \mathrm{~h}=6 \mathrm{~mm}$,

- joining parameters: $\mathrm{V}_{\mathrm{n}}=710 \mathrm{rev} / \mathrm{min}, \mathrm{V}_{\mathrm{z}}=140 \mathrm{~mm} / \mathrm{min}, \alpha_{\mathrm{z}}=88^{\circ}$.

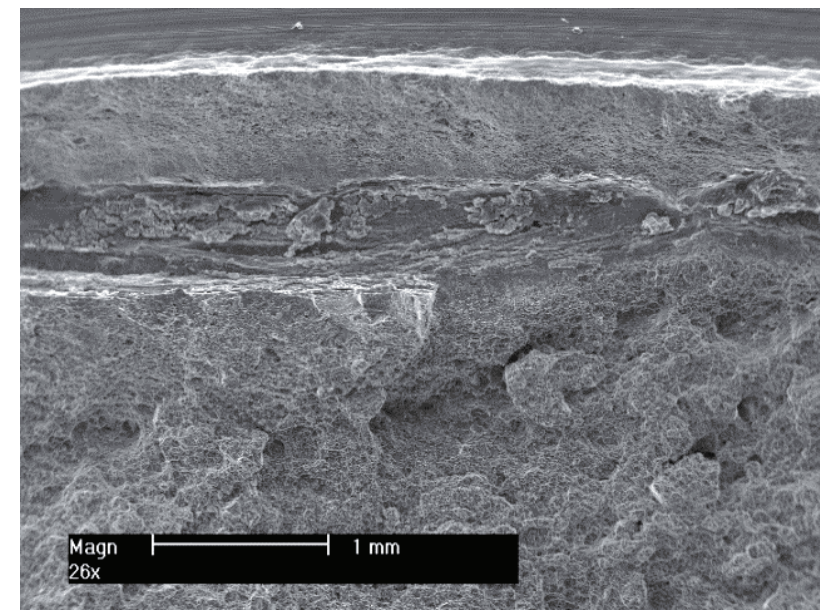

a)

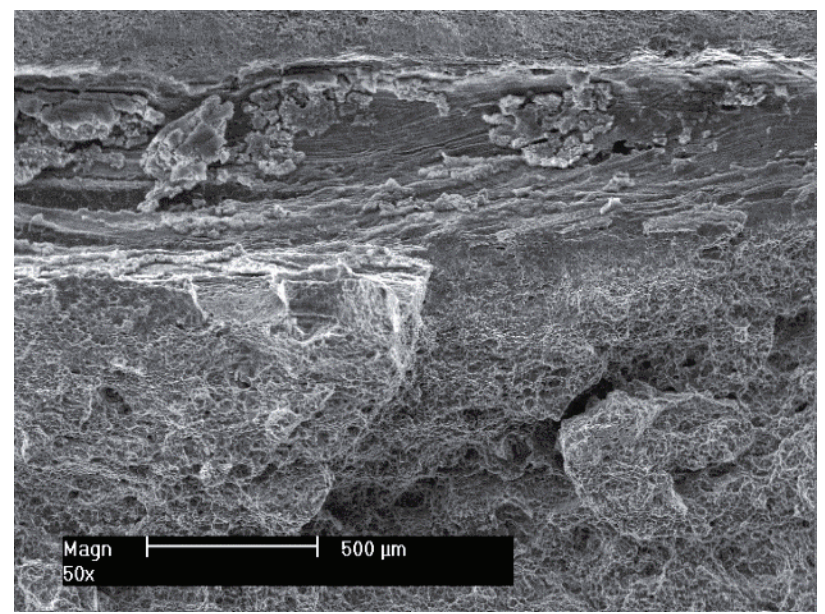

b)

Fig. 7. Fracture of sample with welding defect-incomplete fusion, a), b) different magnifications

Fracture of sample with welding defect - separation, is shown in Fig. 8. This sample was joined using tool with regular pin on both sides with the same parameters:

- tool parameters: $\mathrm{D}=26 \mathrm{~mm}, \mathrm{~d}=9 \mathrm{~mm}, \mathrm{~h}=8.6 \mathrm{~mm}$.

- joining parameters: $\mathrm{V}_{\mathrm{n}}=440 \mathrm{rev} / \mathrm{min}, \mathrm{V}_{\mathrm{z}}=224 \mathrm{~mm} / \mathrm{min}, \alpha_{\mathrm{z}}=88.5^{\circ}$.



a)



b)

Fig. 8. Fracture of sample with welding defect-separation, a), b) different magnifications

Fractures of samples with welding defect - separation, are shown in Fig. 9a and 9b. These samples were joined using:

a) tool with regular pin on both sides with the same parameters:

- tool parameters: $\mathrm{D}=20 \mathrm{~mm}, \mathrm{~d}=6 \mathrm{~mm}, \mathrm{~h}=6 \mathrm{~mm}$,

- joining parameters: $\mathrm{V}_{\mathrm{n}}=900 \mathrm{rev} / \mathrm{min}, \mathrm{V}_{\mathrm{z}}=140 \mathrm{~mm} / \mathrm{min}, \alpha_{\mathrm{z}}=88.5^{\circ}$.

b) TRI-FLUTE tool on both sides with the same parameters;

- tool parameters: $\mathrm{D}=20 \mathrm{~mm}, \mathrm{~d}=6 \mathrm{~mm}, \mathrm{~h}=5.8 \mathrm{~mm}$,

- joining parameters: $\mathrm{V}_{\mathrm{n}}=560 \mathrm{rev} / \mathrm{min}, \mathrm{V}_{\mathrm{z}}=224 \mathrm{~mm} / \mathrm{min}, \alpha_{\mathrm{z}}=88.5^{\circ}$. 


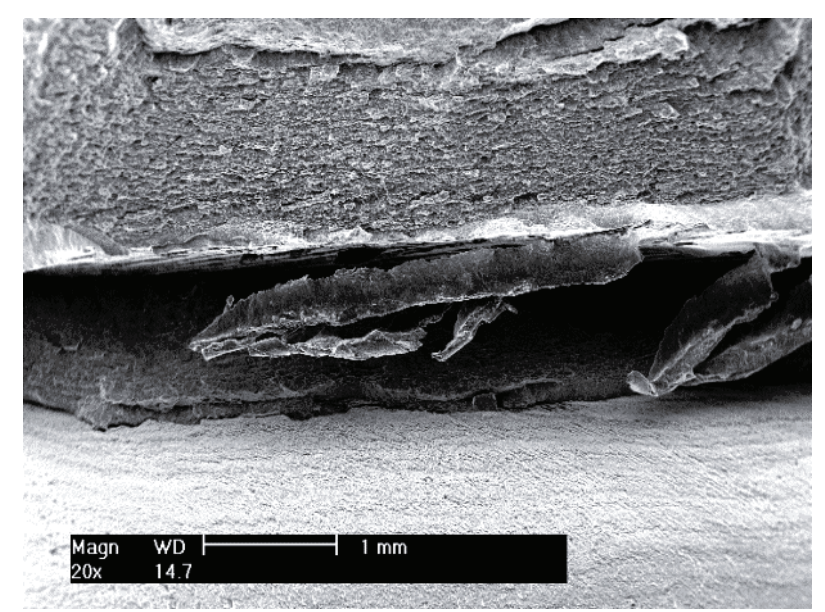

a)

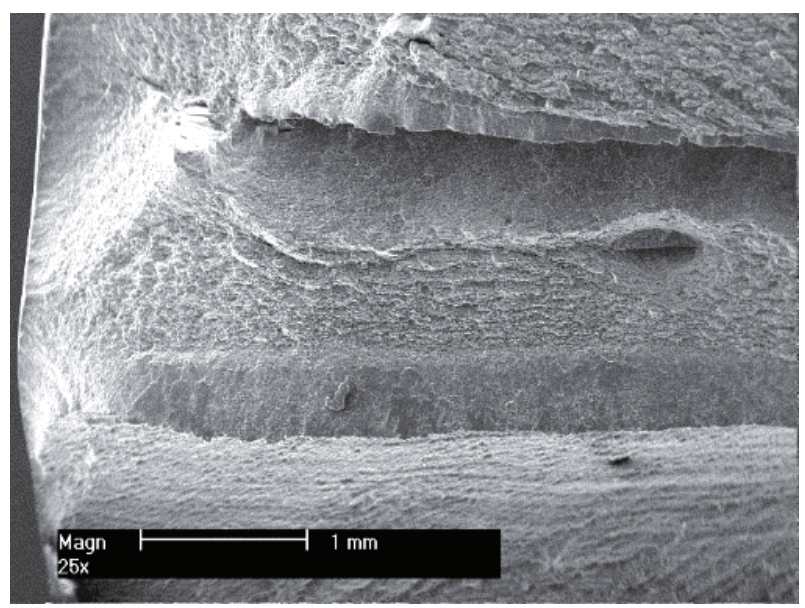

b)

Fig. 9. Fractures of samples with welding defect-separation, a), b) different tools and parameters

Fracture of sample with welding defect - crack, is shown in Fig. 10. This sample was joined using TRI-FLUTE tool on both sides with the same parameters:

- tool parameters: $\mathrm{D}=20 \mathrm{~mm}, \mathrm{~d}=6 \mathrm{~mm}, \mathrm{~h}=5.8 \mathrm{~mm}$,

- joining parameters: $\mathrm{V}_{\mathrm{n}}=560 \mathrm{rev} / \mathrm{min}, \mathrm{V}_{\mathrm{z}}=140 \mathrm{~mm} / \mathrm{min}, \alpha_{\mathrm{z}}=88.5^{\circ}$.

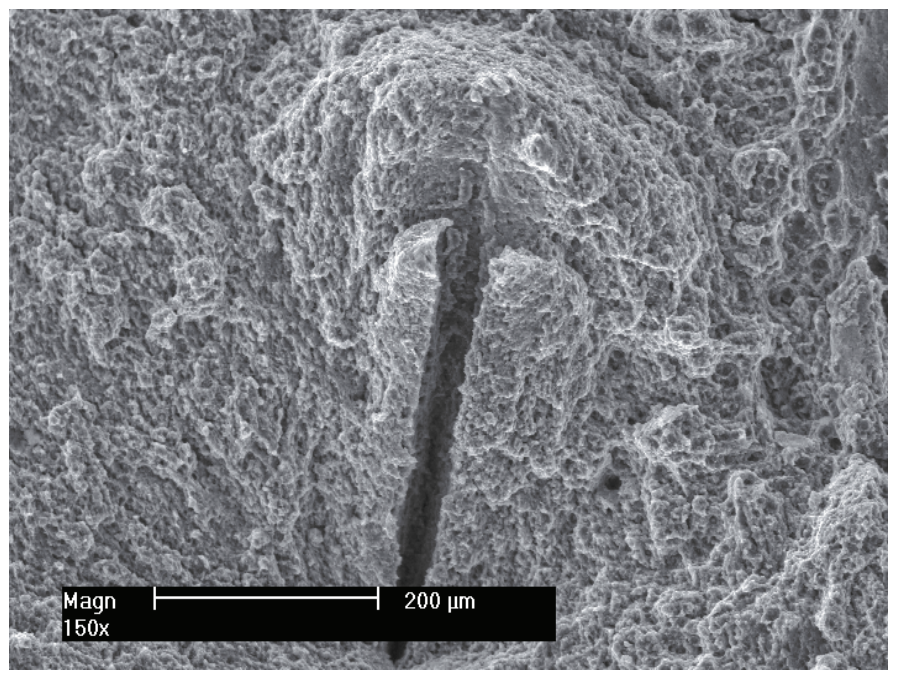

Fig. 10. Fracture of sample with welding defect-crack

\section{Summary}

An analysis of fracture surfaces of samples, after impact test of Charpy method, joined by Friction Stir Welding with different tools and parameters was performed. The analysis has shown that there is the influence of the joining parameters and chosen tools for the possibility of occurrence welding defects in joints.

Friction Stir Welding allows to make joints with proper structure and high strength properties. However, the incorrect selection of welding parameters and tools may cause welding defects. Welding defects detected in the structure of joints after impact studies were: incomplete fusion, separations dissection, and cracks.

The occurrence of defects in welding greatly reduces the mechanical properties of joints. The development of welding technology consisting in selecting the proper tools and parameters allows reducing the likelihood of existence welding defects and obtaining joint with correct structure and high strength properties. 
During the development of friction stir welding technology, tools with regular pins and with TRI-FLUTE pin, with different dimensions, were used. The best results, in terms of structure homogeneity and the absence of welding defects, were achieved for the tool with TRI-FLUTE pin and joining parameters: $\mathrm{V}_{\mathrm{n}}=450 \mathrm{rev} / \mathrm{min}, \mathrm{V}_{\mathrm{z}}=180 \mathrm{~mm} / \mathrm{min}, \alpha_{\mathrm{z}}=88.5^{\circ}$.

\section{References}

[1] Czechowski, M., Effect of anodic polarization on stress corrosion cracking of some aluminum alloys, Advances in Materials Science, Vol. 7, No. 1(11), pp. 13-20, 2007.

[2] Czechowski, M., Low-cycle fatigue of friction stir welded Al-Mg alloys, Journal of Materials Processing Technology, 164-165, 1001-1006, 2005.

[3] Czechowski, M., Własności złączy doczołowych blach ze stopów Al-Mg spajanych różnymi metodami, Materiały i Technologie, Politechnika Gdańska, Nr 1(1), Gdańsk 2003.

[4] Dudzik, K., Influence of joining method for mechanical properties of 7020 aluminum alloy joints, Journal of KONES Powertrain and Transport, Vol. 20, No. 1, pp. 71-76, Jurata 2013.

[5] Dudzik, K., Charchalis, A., Influence of Friction Stir Welding on Hardness Distribution in Joints of AlZn5Mg1 Alloy, Solid State Phenomena, Trans Tech Publications, Mechatronic Systems and Materials V, pp. 430-435, Switzerland 2013.

[6] Dudzik, K., Czechowski, M., Analysis of possible shipbuilding application of Friction Stir Welding (FSW) method to joining elements made of AlZn5Mgl alloy, Polish Maritime Research No. 4, 2009.

[7] Dudzik, K., Czechowski, M., The properties of AlZn5Mg1 (AW-7020) alloys welded by new technology friction stir welding, Journal of KONES Powertrain and Transport, Vol. 15, No. 3, Warszawa 2008. 